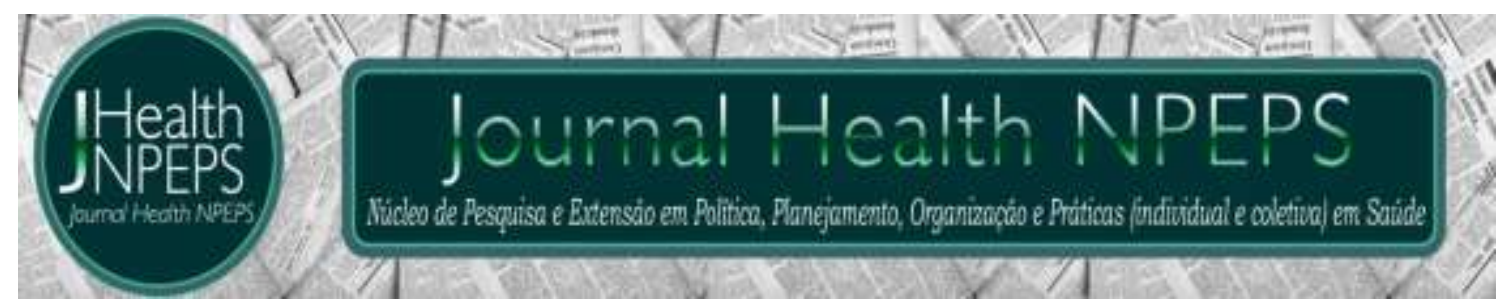

http://dx.doi.org/10.30681/252610104207

EDITORIAL

\title{
Anti-hegemonia em Bioética: alguns apontamentos
}

Anti-hegemony in bioethics: some notes

Anti-hegemonía en bioética: algunas notas

\section{Ludmila Marengo Garcia de Carvalho', Simone Gonçalves Senna²}

Após a publicação do livro Principles of biomedical ethics de 1979, em Nova lorque (EUA), que inseriu um quarto princípio fundamental à bioética somados aos propostos pelo Relatório de Belmont, publicado em 1978, também nos Estados Unidos, podemos inferir que estava inaugurada a bioética principialista. Tal bioética elencou os seguintes princípios: autonomia, beneficência, não-maleficência e justiça, sendo a não-maleficência, o princípio incorporado pelo livro supracitado'.

É importante destacar que o modelo da bioética principialista surgiu a partir da necessidade de intensificação das discussões no âmbito da reflexão sobre os conflitos e dilemas morais da ética médica e biomédica, sendo aplicado, sobretudo, no campo dos conflitos abordados pela bioética7.

Sendo assim, a bioética principialista passou a ser amplamente utilizada e a exercer influência para a realização das análises éticas de pesquisas envolvendo seres humanos a nível global, assumindo caráter hegemônico ${ }^{1}$.

${ }^{1}$ Enfermeira. Especialista em Auditoria e Gestão da Qualidade Aplicados aos Serviços de Saúde. E-mail: ludmila.pesquisa@yahoo.com.br ORCID ID: https://orcid.org/0000-0002-4946-205X

${ }^{2}$ Bióloga. Doutora em Ciências (Microbiologia). E-mail: simonegsenna@yahoo.com.br ORCID ID: https://orcid.org/0000-0002-6665-0781

Este artigo está licenciado sob forma de uma licença Creative Commons Atribuição 4.0 Internacional, que permite uso irrestrito, distribuição e reprodução em qualquer meio, desde que a publicação original seja corretamente citada. 
O processo de globalização econômica mundial intensificou as desigualdades entre os países dos hemisférios norte e sul. Ressalta-se aqui, que se refere como sul as regiões submetidas ao colonialismo e que, com raras exceções, não atingiram níveis de desenvolvimento socioeconômico semelhante à Europa e América no Norte, chamados de norte global ${ }^{3}$.

Entretanto, embora a bioética principialista desempenhe um papel de importância, sendo amplamente utilizada visto a hegemonia dos países centrais, defensores de tal prática, nem sempre seus princípios podem ser aplicados globalmente, principalmente quando nos referimos à países periféricos e/ou que possuam sociedade em situação de vulnerabilidade².

Por conseguinte, é importante destacar a relevância da gênese, fortalecimento e disseminação da bioética de intervenção como meio de proteção à população supracitada através da possibilidade de discussões mais amplas e específicas para as diversas sociedades, sobretudo às expostas às situações de vulnerabilidade econômica e social. Reiterando o que autores ${ }^{3}$ destacam para a superação do pensamento abissal, na pungência de alternativas epistemológicas originadas do sul, como forma de resistência a dominação do norte, esse caminho precisa ser trilhado através da ecologia dos saberes.

Nesse sentido, é importante se atentar às tentativas de os países do Sul realizarem um diálogo com os conceitos produzidos nos países do Norte, o que pode levar ao risco de subordinação além da monopolização do controle da subjetividade, cultura e conhecimento ${ }^{3}$. De acordo com Santos e Meneses ${ }^{3}$ o "colonialismo foi também uma dominação epistemológica" que proporcionou iniquidades nas relações, tendendo a suprimir os saberes constituídos nas nações colonizadas. Essas relações injustamente desiguais produziram o que denomina como pensamento abissal, que torna invisível o que se opõe levando a uma ausência de dialética ${ }^{3}$.

Atualmente, encontra-se em desenvolvimento o programa "Fogarty International", implementado pelo NIH. Conforme descrito por Helmmann e colaboradores ${ }^{4}$, o programa está sendo realizado em países de baixa e média renda e sua aplicação incentiva as práticas principialistas em detrimento do desenvolvimento de ações aplicadas ao contexto da realidade específica de 
cada sociedade. Ainda segundo os autores, desde o ano 2000, 20 programas de treinamento formaram aproximadamente 600 estagiários de mestrado de 74 instituições da África, Ásia, América Latina, Europa Oriental e Oriente Médio ${ }^{4}$. Neste contexto, é possível inferir que pela maneira com que esse programa de treinamento tem sido desenvolvido, está desempenhando um papel de imperialismo moral indireto, visto que desenvolve ações destinadas a convencer e captar pessoas em países com população vulnerável, que posteriormente são incentivadas a se tornar membros de Comitê de Ética em Pesquisa e órgãos governamentais que desenvolvem as análises éticas das pesquisas ${ }^{4}$.

Nesse sentido, o programa supracitado vem em desencontro à construção de uma bioética que intervenha diretamente na realidade específica. Esse fato evidencia a necessidade do desenvolvimento de premissas capazes de embasar práticas interferentes no contexto socioeconômico e cultural e que percebam a pluralidade moral presente nas sociedades contemporâneas ${ }^{12}$.

Tal cenário demonstra no contexto da bioética um colonialismo epistemológico evidente, na medida em que os países periféricos ficam sujeitos às determinações dos países centrais, evidenciando assim a dominação do pensamento abissal, como Santos e Meneses ${ }^{3}$ destacam evidenciando o "epistemicídio". Os autores argumentam que o epistemicídio vem ampliando a linha abissal e proporcionando "a não-existência, a invisibilidade radical e a irrelevância" através do que o autor denomina sociologia das ausências e da sociologia das emergências surgem formas de resistência a esse cenário.

Nesse momento, seria interessante considerar a abordagem através das Epistemologias do Sul, conforme os autores as descreve "conjunto de intervenções epistemológicas que denunciam a supressão, valorizam os saberes que resistiram com êxito e investigam as condições de um diálogo horizontal entre saberes". 0 trabalho desses autores propõe reaver práticas e saberes de diversos grupos sociais, que devido ao processo de colonização, foram subordinados social e historicamente aos saberes hegemônicos, os quais eram considerados os únicos saberes válidos. 
Santos e Meneses ${ }^{3}$ referem ainda, que cada saber existe em meio a outros saberes sendo que nenhum se basta, o que leva a uma contínua necessidade da relação com outros saberes. Dessa forma, não há a intenção de combate entre os saberes do hemisfério norte e do sul, entretanto, principalmente dentro da ética da vida, precisamos saber filtrar o que de fato, atende a nossa realidade enquanto hemisfério sul.

É interessante ressaltar, que através da implementação de um diálogo horizontal de saberes, entre realidades diferentes - sul e norte - torna-se possível promover construções epistemológicas que, em conjunto, colaborem para a melhor compreensão dos fenômenos bioéticos, visando uma realidade melhor para todos.

A disseminação de propostas de correntes para além do modelo principialista gerou impacto no pensamento em Bioética, pois começaram a surgir de fortes críticas, principalmente vindas de pensadores de países e regiões em que as condições para a proteção dos participantes de pesquisas se diferem substancialmente das propostas do modelo principialista. Com o desenvolvimento da pesquisa em Bioética no Brasil, alguns autores se destacaram ao rebater a adoção de teorias éticas hegemônicas com vistas à formulação de uma teoria que se adequasse às necessidades de um país periférico com grave quadro de exclusão social e vulnerabilidade ${ }^{8}$.

Feitosa e Nascimento ${ }^{9}$ descrevem que a partir da contribuição de Volnei Garrafa, a Bioética tem seu período de desenvolvimento no Brasil. Ainda, segundo os autores, a gênese da bioética intervencionista se dá a partir dos trabalhos supracitados, somados à "Conferência Bioética fuerte: una perspectiva periférica a las teorías bioéticas tradicionales", no " $3^{\circ}$ Congresso de Bioética da América Latina em 2000"e, principalmente, com a realização do "60 Congresso Mundial de Bioética" (2002) e a publicação do trabalho Bioética, poder e injustiça: por uma ética de intervenção, produção conjunta de Garrafa e Porto, de 2002. A partir desse contexto foi elaborada uma teoria de inclusão da realidade socioeconômica, problemas de saúde e biotecnológicos provenientes dessa realidade.

Após esse período e até a atualidade, há várias publicações de trabalhos referentes à bioética de intervenção, fato relevante para a sua 
disseminação e conscientização frente à proteção das populações mais vulneráveis.

Destaca-se ainda a promulgação da Declaração Universal Sobre Bioética e Direitos Humanos (DUBDH) em 2005, cuja essência é o respeito ao ser humano. Essa declaração tem força universal e ressalta a importância da dignidade humana, direitos humanos e das liberdades fundamentais. Através da DUBDH foram elencados 15 princípios a serem respeitados nas análises éticas: Dignidade Humana e Direitos Humanos, Benefício e Dano, Autonomia e Responsabilidade Individual, Consentimento, Indivíduos sem a Capacidade para Consentir, Respeito pela Vulnerabilidade Humana e pela Integridade Individual, Privacidade e Confidencialidade, Igualdade, Justiça e Equidade, Não-Discriminação e Não-Estigmatização, Respeito pela Diversidade Cultural e pelo Pluralismo, Solidariedade e Cooperação, Responsabilidade Social e Saúde, Compartilhamento de Benefícios, Proteção das Gerações Futuras e Proteção do Meio Ambiente, da Biosfera e da Biodiversidade.

Os princípios promulgados na Declaração supracitada vão além da Bioética Principialista: pode-se realmente considerar a "autonomia legítima" diante de condições de vulnerabilidade em que se encontram determinadas sociedades? Além disso, até que ponto estão sendo respeitados os princípios da beneficência, não-maleficência e justiça? Ressalta-se aqui, os cenários nas diferentes sociedades, pois o respeito às suas peculiaridades é fundamental para desenvolver a proteção adequada às populações em situação de vulnerabilidade. Nem sempre podemos garantir que não estão sendo realizadas intervenções que realmente não prejudiquem os indivíduos. Tais discussões geram outras correntes de pensamento não antiprincipialistas, mas principalmente "voltadas para a defesa dos interesses e dos direitos históricos das populações econômica e socialmente excluídas do processo desenvolvimentista mundial"10,11.

No Brasil, estão se desenvolvendo formas de resistência à bioética defendida em países centrais. Uma questão que se apresentou de maneira enfática nesse sentido, foi o fato de o Conselho Federal de Medicina não reconhecer como adequadas as mudanças introduzidas na Declaração de Helsinque a partir de 2013. Esta promoveu alterações que proporcionaram 
maior vulnerabilidade dos participantes de pesquisa. Garrafa e Lorenzo $^{5}$ destacaram que principalmente os tópicos 19, 29 e 30 relacionados ao uso de placebo foram os responsáveis por esse aumento da vulnerabilidade.

Ainda nesse sentido, ressalta-se o trabalho realizado pelo Sistema CEP/Conep, que desde 1996 desenvolve a regulação de proteção ética aos participantes de pesquisa no país. Esse sistema está vinculado ao Conselho Nacional de Saúde (CNS), que é um dos principais organismos de controle social no Brasil. Podemos inferir que o Sistema CEP/Conep vem se constituindo através da proposta da ecologia dos saberes, na medida em que a sua organização ocorre através do controle da sociedade.

Atualmente, para o registro inicial ou renovação de registro de um Comitê de Ética (CEP), é necessário um representante de usuários para cada sete membros de CEP, processo relevante para a implementação efetiva, fiel e igualitária nas análises éticas para a garantia da proteção dos participantes de pesquisa no país. Tal obrigatoriedade está estabelecida através da Resolução 240/1997 e reforçada pela Norma Operacional 001/2013.

Diante do exposto, é relevante destacar a nossa responsabilidade frente a implementação de urgentes discussões e ações educativas em bioética para além da corrente principialista, enfatizando não apenas sensibilizar, mas efetivar a importância de atuações pertinentes à diversas condições de vulnerabilidade existentes.

\section{REFERÊNCIAS}

1. Garrafa V, Martorell LB, Nascimento WF do. Críticas ao principialismo em bioética: perspectivas desde o norte e desde o sul. Saúde soc. 2016; 25(2):442-51.

2. Morais TCA, Monteiro PS. Conceitos de vulnerabilidade humana e integridade individual para a bioética. Rev Bioética. 2017; 25(2):311-9.

3. Santos BDS, Meneses MP. Epistemologias do Sul. Rev Lusófona Educ. 2009; 13:183-9.

4. Hellmann F, Garrafa V, Schlemper BR, Bittencourt SC. Moral Imperialism in NIH Fogarty Training Program and the Continuing Unethical Trials in 
Poor Countries: A Rejoinder. Arch Med Res. 2016; 47(1):67-8.

5. Garrafa V, Lorenzo C. Moral imperialism and multi-centric clinical trials in peripheral countries. Cad Saude Publica. 2008; 24(10):2219-26.

6. Beauchamp T, Childress J. Principles of Biomedical Ethics, 5th edn. In: Oxford University Press [Internet]. Oxford; 2001. p. 454.

7. Schramm FR, Palácios M, Rego S. O modelo bioético principialista para a análise da moralidade da pesquisa científica envolvendo seres humanos ainda é satisfatório? Cien Saude Colet. 2008; 12(3):361-70.

8. Oliveira MJ, Osman EMRO. Pluralismo bioético: contribuições latinoamericanas para uma bioética em perspectiva decolonial. Rev Bioética. 2017; 25(1):52-60.

9. Feitosa SF, Nascimento WF do. A bioética de intervenção no contexto do pensamento latino-americano contemporâneo. Rev Bioética. 2015; 23(2):277-84.

10. Porto D, Garrafa V. A influência da Reforma Sanitária na construção das bioéticas brasileiras. Cien Saude Colet. 2011; 16(suppl 1):719-29.

11. Silva LES, Drummond A, Garrafa V. Bioética de intervenção: uma prática politizada na responsabilidade social. Universitas. 2011; 9(2):111-9.

12. Oliveira A, Villapouca K, Barroso W. Pesrpectivas epistemológicas da bioética brasileira a parit da teoria de Thomas Kuhn. Rev Bras Bioética. 2005; 1(4):1-23.

Como citar este artigo: Carvalho LMG, Senna SG. Educação anti-hegemônica em bioética no Brasil. J Health NPEPS. 2019; 4(2):7-13. 